\title{
Modern Methods to Explore GPCR Signalling in Live Cells
}

\author{
Emma Tripp ${ }^{1}$, Shannon O'Brien (Guest Editor) ${ }^{2}$, and Davide Calebiro ${ }^{1}$ \\ ${ }^{1}$ University of Birmingham College of Medical and Dental Sciences \\ ${ }^{2}$ University of Birmingham
}

February 23, 2022

\begin{abstract}
Investigating the intricate mechanisms of G protein-coupled receptor (GPCR) signalling in living cells is far from trivial. Over the last 20 years, the rise of genetically encoded resonance energy transfer (RET) sensors has shed new light onto the mechanisms of GPCR signalling. Such findings have challenged classical views on GPCR signalling and enhanced our understanding of the spatiotemporal dimensions of GPCR activity, leading to the discovery of endosomal GPCR signalling. This review highlights the use of RET sensors to monitor GPCR signalling in real-time and in live cells, focusing on GPCR activation and trafficking, and second messenger activity. It explores the physiological relevance of illustrative cases of endosomal signalling and discusses potential avenues to improve RET approaches to further explore endogenous GPCR activity in physiologically relevant contexts.
\end{abstract}

Modern Methods to Explore GPCR Signalling in Live Cells

Emma Tripp, Shannon O'Brien, and Davide Calebiro

Institute of Metabolism and Systems Research, University of Birmingham, UK

Centre of Membrane Proteins and Receptors (COMPARE), Universities of Nottingham and Birmingham, UK

Abstract

Investigating the intricate mechanisms of G protein-coupled receptor (GPCR) signalling in living cells is far from trivial. Over the last 20 years, the rise of genetically encoded resonance energy transfer (RET) sensors has shed new light onto the mechanisms of GPCR signalling. Such findings have challenged classical views on GPCR signalling and enhanced our understanding of the spatiotemporal dimensions of GPCR activity, leading to the discovery of endosomal GPCR signalling. This review highlights the use of RET sensors to monitor GPCR signalling in real-time and in live cells, focusing on GPCR activation and trafficking, and second messenger activity. It explores the physiological relevance of illustrative cases of endosomal signalling and discusses potential avenues to improve RET approaches to further explore endogenous GPCR activity in physiologically relevant contexts.

Introduction

G protein-coupled receptors (GPCRs) are encoded by approximately 800 different genes and form the largest family of membrane proteins in the human genome. GPCRs mediate the effects of a variety of extracellular cues, from neurotransmitters to photons, and consequently, are fundamental regulators of physiological homeostasis (Calebiro and Godbole, 2018). It is therefore unsurprising that around one third of current pharmaceuticals target this receptor family (Calebiro and Godbole, 2018). Despite this, several important aspects of GPCR signalling remain insufficiently understood. In the classical view of GPCR signalling, ligandactivated GPCRs signal at the plasma membrane via heterotrimeric G proteins, often rapidly desensitise, and undergo arrestin-mediated internalisation (Calebiro and Godbole, 2018). Signalling competence can 
then be restored by GPCR re-sensitisation and recycling back to the plasma membrane (Calebiro and Godbole, 2018). However, evidence gathered over the last decade indicates that select GPCRs can also signal through heterotrimeric $\mathrm{G}$ proteins at distinct intracellular sites and that the resulting signals may be important for physiological functions (Irannejad et al., 2013, Eichel and von Zastrow, 2018, Calebiro et al., 2009, Godbole et al., 2017, Yarwood et al., 2017). Evidence of intracellular GPCR signalling has been largely obtained through the application of genetically encoded fluorescence/bioluminescence resonance energy transfer (FRET/BRET)-based sensors that measure dynamic protein-protein and intramolecular interactions in real-time and in live cells. Such methodologies have a much higher temporal resolution than endpoint biochemical assays and have substantially improved our understanding of GPCR signalling. Above all, they have revealed that GPCR signalling is not limited to the plasma membrane, but instead is a highly regulated event that works in combination with GPCR trafficking to enhance the specificity of signalling in response to distinct physiological cues.

\section{The principles of FRET/BRET and split luciferase-based methods}

FRET technology harnesses the natural phenomenon that occurs when two complementary fluorophores are in close proximity and an excited fluorophore non-radiatively transfers energy, through dipole-dipole coupling, to an acceptor fluorophore (Figure 1A). The efficiency of the energy transfer is dictated by three main factors: (1) the emission spectrum of the donor and excitation spectrum of the acceptor fluorophores, which must at least partially overlap; (2) the distance between the two fluorophores, which should be very short (typically less than 10nm); and (3) the relative orientation of the donor and acceptor dipoles in space, which must be favourable (Sekar and Periasamy, 2003). FRET requires external excitation of the donor fluorophore and can be measured using a fluorescence microscope or fluorimeter to determine protein-protein interactions and/or conformational changes (Sekar and Periasamy, 2003).
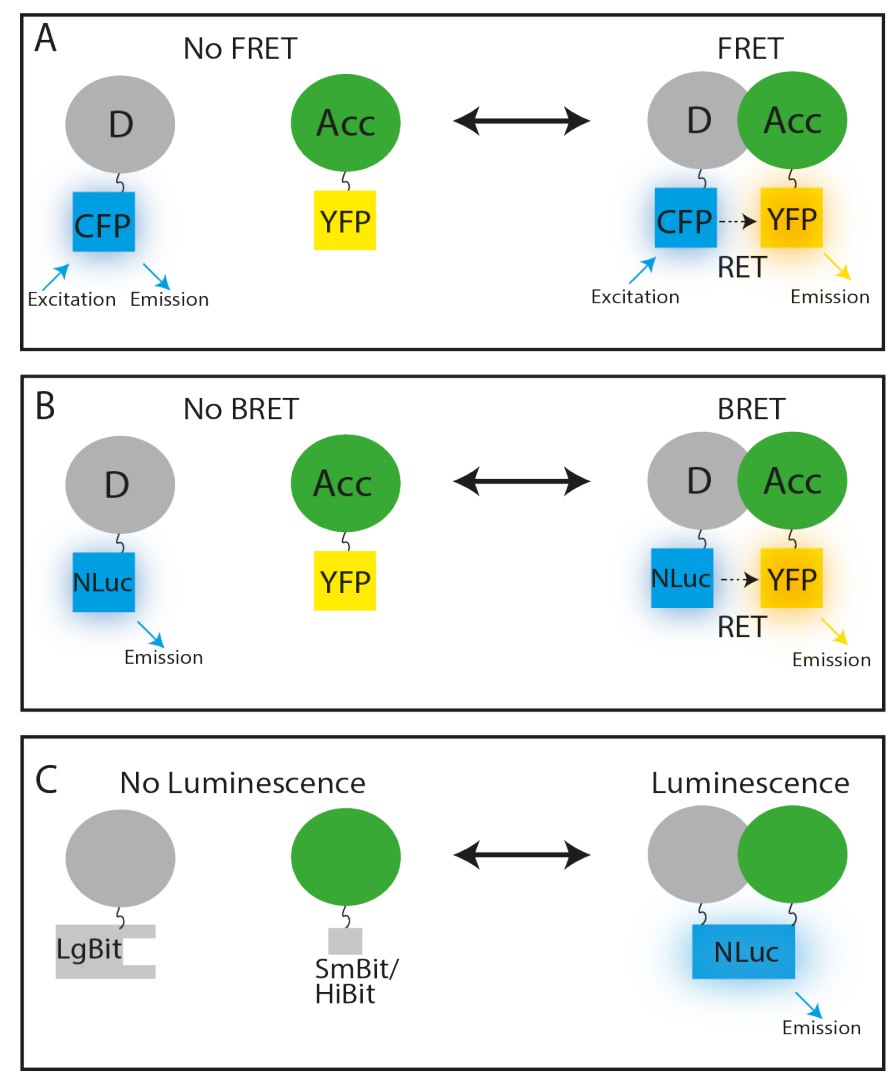
BRET, like FRET, is also used to investigate conformational changes and/or protein-protein interactions. However, BRET uses bioluminescent luciferase enzymes as donor molecules rather than fluorophores and does not require excitation from an external light source - a process that can cause photobleaching, autofluorescence, and light scattering. This means BRET has a very low background and increased signal-to-noise ratio compared to FRET (Dale et al., 2019). Renilla luciferase (RLuc), isolated from the Renilla reniformis sea pansy, was one of the first luciferase enzymes to be used in BRET (Dale et al., 2019). In the case of RLuc, the luciferase enzyme catalyses the ATP-independent oxidation of a luciferase substrate, coelenterazine (Dale et al., 2019). The luciferase donor molecule non-radiatively transfers energy to an acceptor fluorophore if the pair is in close proximity, in a manner similar to FRET (Figure 1B). One of the latest developments in BRET has been the introduction of a superior luciferase enzyme called Nanoluciferase (NLuc) (Dale et al., 2019). NLuc is a $19 \mathrm{kDa}$ subunit derived from a larger, multi-subunit luciferase isolated from the deep-sea shrimp Oplophorus gracilirostris (Hall et al., 2012). NLuc has several advantages over RLuc: it is more stable; it is approximately 150 times brighter; and its smaller size means steric hindrance is less likely (Dale et al., 2019).

NLuc has been further exploited to produce an NLuc-derived split luciferase reporter system termed NanoBiT. NanoBiT is composed of two NLuc derived fragments: an 11 amino acid-long small bit (Sm$\mathrm{BiT})$ or high bit (HiBiT) fragment; and a second large bit fragment (LgBiT) (17.6 kDa). These fragments are genetically fused to separate parts of the same protein or two distinct proteins. When in proximity, the two fragments can reconstitute and produce a luminescent signal. HiBiT is commonly used for ligand binding assays (Soave et al., 2016, Stoddart et al., 2015), whereas SmBiT is better suited to investigate protein-protein interactions due to its lower affinity for LgBiT (Figure 1C) (Lohse et al., 2012).

\section{RET methods to evaluate GPCR signalling}

\section{cAMP signalling}

Evaluating second messenger production following GPCR activation in live cells was once very challenging. The first RET-based biosensor to be developed was a multimolecular sensor, based on protein kinase A (PKA) subunits, sensitive to cAMP. PKA is a heterotetrameric complex, made up of two catalytic and two regulatory subunits that dissociate upon cAMP binding to the regulatory subunits (Kim et al., 2007). By monitoring FRET between the fluorescein labelled catalytic subunits and the rhodamine labelled regulatory subunits, changes in intracellular cAMP levels could be followed in real time. Pioneering work with this sensor, named FlCRhR, enabled the visualisation of cAMP compartmentalisation for the first time (Hempel et al., 1996, Bacskai et al., 1993, Adams et al., 1991).

Despite this, the use of FlCRhR was practically challenging, mainly due to the requirement to purify PKA subunits, label them ex vivo, and subsequently microinject them into live cells. Nearly ten years later, with the introduction of fluorescent proteins, a new generation of genetically encoded FRET sensors based on the FlCRhR concept were created (Zaccolo et al., 2000). This enabled direct imaging of cAMP and PKA activation in both single cells and multicellular preparations (Janetopoulos et al., 2001, Lissandron et al., 2005, Zaccolo et al., 2000).

However, multimolecular cAMP sensors have their own limitations. Firstly, to outcompete the binding of endogenous non-fluorescent PKA subunits, they must be expressed at a relatively high concentration, which may lead to cAMP buffering and distortion of cAMP dynamics (Paramonov et al., 2015). Secondly, they are catalytically active, which may affect downstream signalling (Paramonov et al., 2015). Thirdly, the fluorescently labelled regulatory and catalytic PKA subunits are usually expressed by separate vectors, which often makes achieving equal expression levels challenging (Zaccolo et al., 2000).

These potential limitations fostered the development of a new generation of unimolecular cAMP sensors. The majority of these sensors are based upon Epac, a cAMP-activated guanine-exchange factor (GEF) for the small GTPase Rap1 (Calebiro and Maiellaro, 2014). cAMP binding to Epac induces a conformational change that exposes an otherwise hidden catalytic domain to activate Rap1 (Calebiro and Maiellaro, 2014). Different cAMP FRET sensors based on Epac1 or, alternatively, a truncated form that expresses the isolated cAMP 
binding domain, were created in parallel by sandwiching Epac1 between two suitable fluorophores (Nikolaev et al., 2004, Ponsioen et al., 2004, DiPilato et al., 2004). Since cAMP binding results in a decrease in FRET, intracellular changes in cAMP can be detected (Nikolaev et al., 2004, Ponsioen et al., 2004, DiPilato et al., 2004). Considering these sensors are based on a single protein, they have a faster response to cAMP binding than multimolecular sensors, thus increasing temporal resolution (Paramonov et al., 2015). In addition, the use of a single encoding vector overcomes the problems associated with unequal expression levels as seen with previous multimolecular cAMP sensors (Paramonov et al., 2015). Importantly, some Epac sensors are also catalytically inactive, avoiding activation of downstream signalling pathways, and, thus, eliminating a potential source of experimental interference (Ponsioen et al., 2004, Nikolaev et al., 2004).

In addition to the previously described cAMP sensors, FRET-based sensors have also been designed to monitor endogenous PKA signalling (Calebiro and Maiellaro, 2014, Zhang et al., 2001). These sensors are called A-Kinase activity reporters (AKARs) and they contain a PKA substrate and a phosphoamino acid binding domain inserted between a FRET donor and acceptor fluorophore (e.g. CFP and YFP) (Zhang et al., 2001). Upon PKA-dependent phosphorylation of the PKA substrate, a conformational change occurs triggering the PKA substrate to interact with the phosphoamino acid binding domain, leading to an increase in FRET between donor and acceptor fluorophores (Calebiro and Maiellaro, 2014, Zhang et al., 2001).

Similar strategies have been followed to design BRET sensors for cAMP. The first BRET-based cAMP sensor was based on PKA (Prinz et al., 2006). By tagging the catalytic PKA subunit with GFP (GFP-C) and regulatory PKA subunits with RLuc (RLuc-RI and RLuc-RII), co-transfection of GFP-C with RLuc regulatory subunit induced a constitutive BRET signal that was reduced upon cAMP binding. As with their FRET counterparts, multimolecular BRET biosensors suffered from some potential limitations. This prompted the development of two unimolecular BRET sensors based on the design of Epac FRET sensors, where the donor fluorophore was replaced with RLuc (Jiang et al., 2007, Barak et al., 2008). One of these sensors, named CAMYEL (cAMP sensor using YFP-Epac-RLuc), uses circularly permuted citrine to enhance the BRET changes upon cAMP binding (Jiang et al., 2007).

More recently, a NLuc-based cAMP BRET sensor has been created. This is based upon a third generation FRET-based cAMP sensor (Klarenbeek et al., 2011) where the donor (mTurquoise) fluorophore has been replaced with NLuc (Masuho et al., 2015). The addition of NLuc, and, thus, the increased signal compared to RLuc, may enable the application of BRET-based cAMP sensors in harder to transfect cell types, and, with improvements to the solubility of bioluminescent substrates, in vivo (Su et al., 2020).

\section{cAMP tools investigating spatiotemporal GPCR signalling}

Genetically encoded cAMP/PKA sensors have greatly advanced our spatial and temporal understanding of cAMP signalling compared to endpoint biochemical methods. Their use has proven essential for the demonstration of compartmentalised GPCR signalling and, more recently, the discovery of GPCR signalling at intracellular sites.

In 2009, FRET-based Epac cAMP sensors were used by two independent groups to show that certain GPCRs can internalise and generate sustained cAMP signals at intracellular sites (Calebiro et al., 2009, Ferrandon et al., 2009). Using a transgenic mouse with ubiquitous expression of a FRET-based Epac cAMP biosensor, Calebiro et al. observed that the thyroid stimulating hormone (TSH) receptor can trigger persistent cAMP signals after internalisation (Calebiro et al., 2009). This phenomenon was further validated using subcellular fractionation methodologies and inhibitors of receptor endocytosis, which prevented persistent cAMP signalling (Calebiro et al., 2009). Intriguingly, it was later shown that sustained TSH receptor signalling is cell-type specific, occurring in primary thyroid cells but not in HEK293 cells (Werthmann et al., 2012).

In parallel, Ferrandon et al. demonstrated, using the same Epac cAMP FRET biosensor, that internalised parathyroid hormone (PTH) receptors are capable of persistent cAMP signals (Ferrandon et al., 2009). This sustained response was dependent on the agonist used as it was triggered by $\mathrm{PTH}_{1-34}$, but not by human parathyroid related peptide $\left(\mathrm{PTHrP}_{1-36}\right)$, suggesting that the sustained response required a tighter interaction of the agonist with the receptor (Ferrandon et al., 2009). 
Measurement of local cAMP and PKA production/activation can be achieved by tethering genetically encoded sensors to specific subcellular compartments. This approach has been applied to measure local cAMP and PKA responses induced by the TSH receptor in thyroid cells (Godbole et al., 2017). After internalisation, TSH receptors were found to be inactive in the early endosome compartment. However, after retrograde trafficking to the trans-Golgi network, the receptor was shown to mediate local cAMP/PKA signalling close to the nucleus (Godbole et al., 2017). By tethering Epac1-cAMP and AKAR2 sensors to the trans-Golgi network or the plasma membrane, it was shown that the TSH receptor has an internalisation-dependent, late-stage, intracellular signalling component that regulates downstream CREB phosphorylation and gene transcription via $\mathrm{G} \alpha_{\mathrm{s}}$ (Godbole et al., 2017).

Similar approaches have been used to target BRET-based cAMP sensors to subcellular compartments. For example, CAMYEL, a Epac-based BRET sensor that is normally present in the cytoplasm, has been compared to a plasma membrane-tethered CAMYEL to study the role of cytosolic and membrane-bound phosphodiesterase (PDE) subtypes, and their importance in the regulation of local cAMP concentrations (Matthiesen and Nielsen, 2011). Tethering CAMYEL, or other similar BRET-based sensors, to local compartments may help to further enhance our understanding of GPCR signalling at intracellular sites.

In addition, a complementary optogenetic approach has been employed to investigate the consequences of local cAMP/PKA signalling. This approach is based on a photoactivated adenylyl cyclase, bPAC, which produces cAMP upon stimulation with blue light (Tsvetanova and von Zastrow, 2014). By targeting bPAC to the cytoplasm, plasma membrane, or early endosomes, Tsvetanova et al. showed that cAMP production in the cytoplasm and early endosomes induces a greater transcriptional response than at the plasma membrane, giving further evidence that internalisation of at least some GPCRs is required to elicit full transcriptional responses. This study further suggests that endosomes can act as a shuttle system from the plasma membrane to intracellular sites, to enhance the efficiency of GPCR signalling (Tsvetanova and von Zastrow, 2014).

\section{Tools to monitor the initial steps in GPCR signalling}

Ligand binding to a GPCR induces a conformational change that enhances the affinity of the receptor for G proteins (Ghanouni et al., 2001). Upon G protein binding, GDP is exchanged for GTP which is present at a higher concentration in the cytoplasm (Bos et al., 2007), initiating G protein activation and further downstream signalling. Soon after RET-based cAMP sensors were created, the first RET biosensor detecting G protein signalling in living Dictyostelium discoideum cells was reported by Janetopoulos et al. (Janetopoulos et al., 2001). In this study, the activation of cAMP chemoattractant receptors was investigated

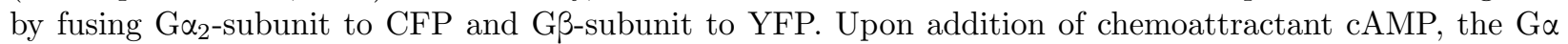
and G $\beta$ subunits dissociate causing a reduction in FRET (Janetopoulos et al., 2001). This was an influential study that inspired other groups to interrogate the dynamics of GPCR-G protein coupling in eukaryotic cells. Initially, studies tested dissociation of the CFP- and YFP-tagged G $\alpha \beta \gamma$ heterotrimer following agonist stimulation of the unmodified receptor (Azpiazu and Gautam, 2004). Further studies measured ligandinduced interaction between the GPCR of interest and G $\alpha$ or G $\beta \gamma$ (Philip et al., 2007, Nobles et al., 2005, Hein et al., 2006). Analogous concepts were utilised for the development of BRET-based assays (Gales et al., 2005, Audet et al., 2008).

FRET/BRET changes between a GPCR and a G protein upon GPCR activation can be relatively small (Wan et al., 2018). Consequently, novel biosensors without membrane anchors were designed to generate higher RET changes upon GPCR activation. Among this type of sensor are conformation-specific nanobodies - binding domains derived from single chain camelid antibodies (Rasmussen et al., 2011). Originally, nanobodies were designed to assist GPCR crystallisation by stabilising the active conformation of a specific GPCR (Rasmussen et al., 2011). However, nanobodies can also be used as reporters of GPCR activation (Irannejad et al., 2013). When expressed in living cells, nanobodies translocate from the cytoplasm to their specific GPCR after it transitions into an active conformation (Irannejad et al., 2013). By fusion with fluorescent proteins, nanobodies can be used both in imaging and FRET/BRET-based assays to assess receptor activation (Figure 2A) (Irannejad et al., 2013) - an approach that has greatly advanced our understanding of endosomal GPCR signalling. 
Within a pivotal study, Irannejad et al. used Nb80-GFP, a nanobody specific for the active conformation of the $\beta_{2}$ adrenoceptor $\left(\beta_{2} \mathrm{AR}\right)$, to reveal that $\beta_{2} \mathrm{AR}$ has a first wave of activation at the plasma membrane, and then a second wave of activation at endosomes (Irannejad et al., 2013). Using another nanobody (Nb37) against active $G \alpha_{\mathrm{s}}$, they further validated that $\mathrm{G}$ proteins are activated within this compartment (Figure 2B) (Irannejad et al., 2013). A similar approach based on Nb37 was used by Godbole et al. giving evidence that the TSH receptor activates endogenous $\mathrm{G} \alpha_{\mathrm{s}}$ proteins on membranes of the trans-Golgi network (Godbole et al., 2017). The resulting localised cAMP production and PKA activation close to the nucleus was required for efficient TSH-dependent CREB phosphorylation and gene transcription (Godbole et al., 2017).

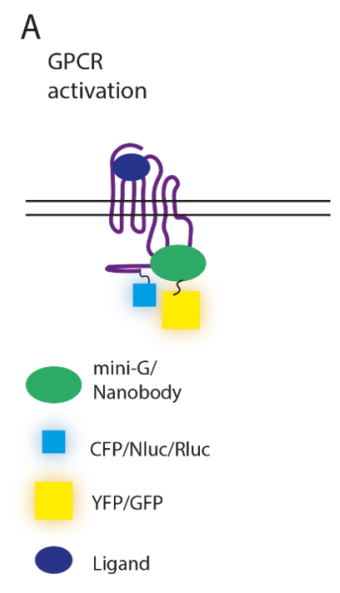

B Compartmentalised GPCR signalling

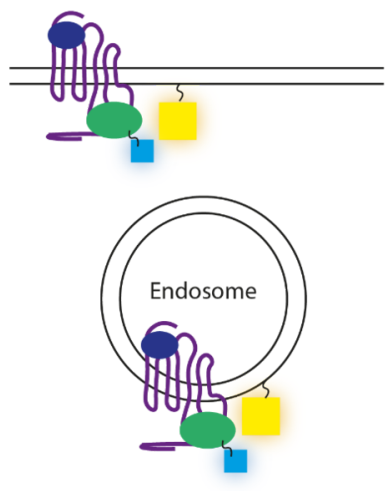

C GPCR trafficking

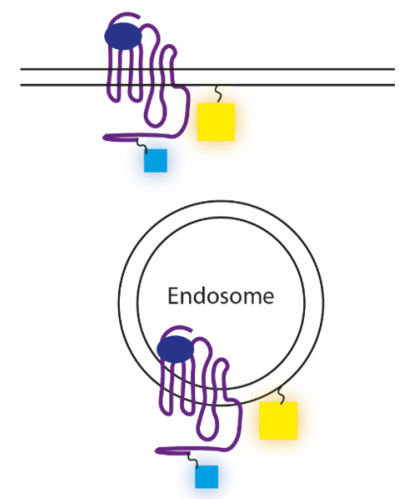

Nanobodies have also been used in combination with NanoBiT approaches to assess endosomal GPCR activation. McGlone et al. fused Nb37 with SmBiT (Nb37-SmBiT) and measured ligand-induced luminescence upon complementation with plasma membrane (CAAX-LgBiT) or early endosome (Endofin-LgBiT) tethered LgBiT, to investigate compartmentalised signalling of the glucagon receptor (GCGR) (McGlone et al., 2021). From this investigation, the group observed that the GCGR signals both at the plasma membrane and the endosomes. In addition, using imaging and luminescence methods, it was found that RAMP2 expression significantly increased intracellular GCGR presence and activity, but had little effect on plasma membrane GCGR activity. Using such methods, RAMP2 was shown to alter the spatiotemporal activity of the GCGR (McGlone et al., 2021).

Considering that GPCRs are now thought to signal from multiple subcellular membranes (Calebiro and Koszegi, 2019), one insufficiently understood aspect is how G proteins access such membranes and whether they are constitutively present at these compartments. BRET-based approaches have been used to investigate $\mathrm{G}$ protein activation and trafficking to subcellular compartments. In an elegant study, Martin et al. monitored the localisation and movement of $\mathrm{G}$ proteins in live cells (Martin and Lambert, 2016). By measuring BRET between $\mathrm{G} \alpha_{\mathrm{s}}-\mathrm{RLuc} 8$ and Venus-tagged intracellular compartment, upon activation of coexpressed $\beta_{2} \mathrm{AR}$ with isoproterenol, $\mathrm{G} \alpha_{\mathrm{s}}$ was shown to leave the plasma membrane and rapidly associate with the ER, mitochondria, and endosomes (Martin and Lambert, 2016). From these results, it was suggested that activation of $G \alpha_{\mathrm{s}}$ causes the protein to lose some of its affinity for the plasma membrane, enter the cytosol, and sample intracellular membrane compartments (Martin and Lambert, 2016).

More recently, mini-G proteins, engineered Ras domains of $\mathrm{G} \alpha$ subunits, have been created to enhance our understanding of GPCR activation in live cells (Nehme et al., 2017, Wan et al., 2018). Mini-G proteins were designed to mimic all main $\mathrm{G}$ protein isoforms $\left(\mathrm{G \alpha}_{\mathrm{i} / \mathrm{o}}, \mathrm{G \alpha}_{\mathrm{s}}, \mathrm{G} \alpha_{\mathrm{q}}\right.$, and $\left.\mathrm{G} \alpha_{12}\right)$, and are frequently used to investigate GPCR coupling specificity, ligand pharmacology, and spatiotemporal GPCR signalling (Figure 2) (Wan et al., 2018). Like nanobodies, mini-G proteins were originally used to improve the stability of 
GPCR-G protein complexes, enabling GPCR crystallisation for structural studies (Nehme et al., 2017). However, mini-G proteins can also be fused to fluorescent or luminescent proteins, as well as self-labelling protein tags, for imaging, FRET, BRET, and luminescence measurements (Wan et al., 2018). Since mini-G proteins are relieved from membrane attachments, they rapidly translocate from the cytoplasm to the active receptor upon stimulation, which can be visualised and measured via microscopy or RET-based approaches (Wan et al., 2018). For example, by monitoring agonist induced mini-G $\alpha_{\mathrm{q}}$ translocation to fluorescently tagged early endosome markers, employing both imaging and BRET-based methodologies, Wright et al. showed that several GPCRs are activated at early endosomes (Wright et al., 2021). In addition, the study suggests that $G \alpha_{\mathrm{q}}$ activation at endosomes requires a first activation event at the plasma membrane and that subsequent $\mathrm{G}$ protein activity at endosomes is either self-sustained or can be enhanced by endocytosed GPCR (Wright et al., 2021). Mini-G proteins have been used in a similar manner to measure endosomal activation of the glucagon-like peptide-1 receptor (GLP-1R) (Lucey et al., 2021) and Golgi activation of $\mathrm{A}_{1}$-adenosine receptors (Wan et al., 2018). The application of mini-G proteins has given novel insight into spatiotemporal GPCR signalling and will undoubtedly help to further characterise our understanding of intracellular GPCR signalling over the coming years.

\section{GPCR trafficking}

RET methods can also be used to investigate GPCR trafficking and further validate the presence of GPCRs at subcellular compartments with high spatiotemporal resolution (Figure 2C). Zacharias et al. introduced the use of FRET to monitor clustering of acylated proteins in the plasma membrane (Zacharias et al., 2002). Using a similar approach, Drake et al. subsequently followed the internalisation of the $\beta_{2} \mathrm{AR}$ by measuring the FRET decrease between CFP tagged $\beta_{2} \mathrm{AR}$ and plasma membrane-tethered mYFP (Drake et al., 2008). Subsequent groups have applied this principle to BRET-based techniques, measuring agonist-induced BRET between a luciferase-tagged GPCR and fluorescently tagged intracellular compartment markers. As BRET offers an improved signal-to-noise ratio compared to FRET, BRET approaches have been used more extensively to characterise GPCR trafficking to various membrane compartments.

In 2011, Lan et al. showed translocation of the $\beta_{2}$ AR from the plasma membrane to early endosomes by monitoring ligand-induced BRET changes between $\beta_{2}$ AR-RLuc8 and Venus-tagged K-Ras (plasma membrane marker) or Venus-tagged Rab5 (early endosome marker) (Lan et al., 2011). In this study, the group were able to demonstrate that only active $\beta_{2}$ ARs internalise, and that associations between $\beta_{2}$ AR protomers are likely transient (Lan et al., 2011). Soon after, the same group used this methodology for the investigation of protein localisation at other subcellular locations. They demonstrated that $\beta_{2} \mathrm{AR}$ traffics through various endosomal compartments, as well as the ER and Golgi (Lan et al., 2012). In addition, they showed the applicability of BRET to determine outer versus inner membrane protein topology at the plasma membrane, ER, and mitochondria (Lan et al., 2012).

In 2016, this methodology was used to validate the significance of clinically relevant Vasopressin 2 receptor $\left(\mathrm{V}_{2} \mathrm{R}\right)$ mutations (Tiulpakov et al., 2016). Further Venus-tagged intracellular compartment markers were validated and added to the previously described toolset to facilitate a yet more detailed understanding of GPCR trafficking via BRET. This included markers of ER to Golgi trafficking (Rab1, Rab6), trans-Golgi trafficking (Rab8), and fast/slow endosomal recycling (Rab4/Rab11) (Tiulpakov et al., 2016). Using this BRET-based technique, the group were able to validate subtle differences in the trafficking profiles of distinct $\mathrm{V}_{2} \mathrm{R}$ mutants, giving further insight into the mechanisms behind nephrogenic syndrome of inappropriate antidiuresis (NSIAD) and nephrogenic diabetes insipidus (Tiulpakov et al., 2016).

BRET has also been shown to be capable of high-throughput endosomal GPCR trafficking assays using plate reader-based detection (Giubilaro et al., 2021). Using such an approach, Giubilaro et al. investigated the properties of biased compounds and their effects on GPCR localisation and trafficking. This led to the identification of a novel Ras and ARF6 inhibitor (Rasarfin), capable of blocking the internalisation of the angiotensin II type 1 receptor (AT1R) and other GPCRs. Rasarfin may have applications as an anti-proliferative agent e.g. for use as an inhibitor of oncogenic cellular responses (Giubilaro et al., 2021). 


\section{The future of RET sensors}

Investigating the physiological relevance of endosomal GPCR signalling remains challenging. Dissecting local signals originating from the plasma membrane versus local signals from intracellular compartments is far from trivial and often requires the combination of multiple FRET/BRET-based measurements and physiological readouts. An example of where this has been demonstrated successfully is for the Neurokinin 1 receptor $\left(\mathrm{NK}_{1} \mathrm{R}\right)$. Jensen et al. reported that the $\mathrm{NK}_{1} \mathrm{R}$ produces sustained signals from endosomes via $\mathrm{G} \alpha_{\mathrm{q}}$, generating signalling cascades that induce nociception (Jensen et al., 2017). Within this study, the group used FRET sensors tethered to the plasma membrane, nucleus, and cytosol to show the significance of endosomal $\mathrm{NK}_{1} \mathrm{R}$ signalling on extracellular signal-regulated kinase (ERK), cAMP, and protein kinase $\mathrm{C}$ (PKC) signalling (Jensen et al., 2017). Substance P induced activation of the aforementioned second messengers could be abolished by inhibiting receptor internalisation (Jensen et al., 2017). Using a BRETbased approach, the group subsequently found that activation of the receptor with Substance P induced receptor trafficking away from the plasma membrane into early endosomes, where the internalised receptor was able to recruit $\mathrm{G} \alpha_{\mathrm{q}}$, suggestive of $\mathrm{G}$ protein dependent signalling by the $\mathrm{NK}_{1} \mathrm{R}$ at endosomes (Jensen et al., 2017). To confirm the physiological relevance of this phenomenon, the group employed endocytosis inhibitors to block $\mathrm{NK}_{1} \mathrm{R}$ internalisation and observed that receptor internalisation was required for sustained Substance P induced excitation of spinal neurons (Jensen et al., 2017). In addition, a cholestanol conjugated $\mathrm{NK}_{1} \mathrm{R}$ antagonist, designed to concentrate in endosomes, was used to validate the specificity of this effect to endosomes (Jensen et al., 2017). This study, and others (Yarwood et al., 2017, Jimenez-Vargas et al., 2020), propose that pharmacological targeting of certain endosomal GPCRs could offer improved and more selective treatments for chronic pain.

Although internalisation inhibitors can be helpful for understanding the effect of internalisation on GPCR signalling, the use of caged agonists/antagonists or protein inhibitors of the GPCR signalling machinery to block downstream responses may help to further investigate intracellular signalling in a more detailed manner. Nanobodies have been used to inhibit GPCRs at selective compartments like the Golgi (Irannejad et al., 2017), and additional tools are being created to block specific G protein isoform subtypes at subcellular compartments, e.g. by tethering the regulator of G protein signalling (RGS) domain of GRK2 to the plasma membrane or the early endosomes to block $\mathrm{G} \alpha_{\mathrm{q}}$ downstream signalling (Wright et al., 2021). It is likely that we will see the development of further toolsets to selectively block GPCR signalling at specific subcellular compartments and, thus, enable a robust interrogation of intracellular signalling and their effects on physiological outputs.

In addition, improving our understanding of endogenous GPCR activity in native cellular systems is essential. Many assays currently rely on the overexpression of receptors in simple, easily transfectable, cell types. However, signalling can be strongly influenced by cellular context. There are some tools available that enable the detection of endogenous GPCR activation. BRET sensors based on an ER/K linker and YFP (BERKY) are an example of such emerging tools (Maziarz et al., 2020). Within these sensors, the BRET donor and acceptor modules (NLuc and YFP, respectively) are separated by a $10 \mathrm{~nm}$-long ER/K $\alpha$ helix linker. On opposite ends of the biosensor lie a membrane anchoring sequence (N-terminus) and an active $\mathrm{G}$ protein detector module (C-terminus) (Maziarz et al., 2020). Given the stochastic bending properties of the $\mathrm{ER} / \mathrm{K} \alpha$ linker and the fact that $\mathrm{G}$ protein activation occurs on cell membranes, these biosensors adopt a bent confirmation when the detector module binds to active $\mathrm{G}$ proteins on membranes, increasing BRET (Maziarz et al., 2020). This enables BERKY sensors to recognise subtype specific G $\alpha$ GTP as well as detect endogenous $\mathrm{G} \alpha$ protein activation (Maziarz et al., 2020). BERKY sensors have been shown to detect subtype specific $\mathrm{G}$ protein activation after stimulation of endogenous opioid and muscarinic receptors in primary neurons (Maziarz et al., 2020). With further modifications, sensors like this could be used to detect endogenous GPCR activation at subcellular compartments.

Endogenous GPCR activity has also been detected by using CRISPR/Cas9-mediated homology-directed repair to add NLuc (C-terminally) onto the receptor of interest, thus facilitating the assessment of GPCR activity under endogenous expression. White et al. used this approach to detect CXC motif chemokine 
receptor 4 (CXCR4) internalisation, trafficking, and $\beta$-arrestin recruitment in HEK293 cells (White et al., 2017). Such methods could also be applicable to more physiologically relevant cell/tissue types via knock-in pluripotent stem cells or even knock-in animals (Merkle et al., 2015).

In summary, RET sensors have dramatically changed our understanding of how GPCRs signal spatially and temporally. They have allowed real-time monitoring of receptor coupling, trafficking, and second messenger activity in live cells, which have all been instrumental towards our understanding of endosomal signalling. If, in the future, we could utilise these methods and other complementary approaches, to investigate endogenous receptors in their native cell types or even in vivo, we should gain a much clearer understanding of the physiological relevance of GPCR signalling at intracellular sites. Not only will such research help to untangle a key emerging mechanism of GPCR signalling, but it may permit more targeted therapeutic approaches for a variety of diseases.

\section{References}

ADAms, S. R., HAROOTUNIAN, A. T., BUECHLER, Y. J., TAYLOR, S. S. \& TSIEN, R. Y. 1991. Fluorescence ratio imaging of cyclic AMP in single cells. Nature, 349, 694-7.

AUdet, N., GAles, C., ARCHER-LAhloU, E., VAlliERES, M., SCHILlER, P. W., BOUVIER, M. \& PINEYRO, G. 2008. Bioluminescence resonance energy transfer assays reveal ligand-specific conformational changes within preformed signaling complexes containing delta-opioid receptors and heterotrimeric $\mathrm{G}$ proteins. J Biol Chem, 283, 15078-88.

AZPIAZU, I. \& GAUTAM, N. 2004. A fluorescence resonance energy transfer-based sensor indicates that receptor access to a G protein is unrestricted in a living mammalian cell. J Biol Chem,279, 27709-18.

BACSKAI, B. J., HOCHNER, B., MAHAUT-SMITH, M., ADAMS, S. R., KAANG, B. K., KANDEL, E. R. \& TSIEN, R. Y. 1993. Spatially resolved dynamics of cAMP and protein kinase A subunits in Aplysia sensory neurons.Science, 260, 222-6.

BARAK, L. S., SALAHPOUR, A., ZHANG, X., MASRI, B., SOTNIKOVA, T. D., RAMSEY, A. J., VIOLIN, J. D., LEFKOWITZ, R. J., CARON, M. G. \& GAINETDINOV, R. R. 2008. Pharmacological characterization of membrane-expressed human trace amine-associated receptor 1 (TAAR1) by a bioluminescence resonance energy transfer cAMP biosensor. Mol Pharmacol, 74, 585-594.

BOS, J. L., REHMANN, H. \& WITTINGHOFER, A. 2007. GEFs and GAPs: critical elements in the control of small G proteins. Cell,129, 865-77.

CALEBIRO, D. \& GODBOLE, A. 2018. Internalization of G-protein-coupled receptors: Implication in receptor function, physiology and diseases.Best Pract Res Clin Endocrinol Metab, 32, 83-91.

CALEBIRO, D. \& KOSZEGI, Z. 2019. The subcellular dynamics of GPCR signaling. Molecular and Cellular Endocrinology, 483,24-30.

CALEBIRO, D. \& MAIELLARO, I. 2014. cAMP signaling microdomains and their observation by optical methods. Front Cell Neurosci,8, 350.

CAlebiro, D., NikOlaeV, V. O., GAGliani, M. C., DE FiliPPis, T., DeES, C., TACChetTi, C., PERSANI, L. \& LOHSE, M. J. 2009. Persistent cAMP-signals triggered by internalized G-protein-coupled receptors.PLoS Biol, 7, e1000172.

DAle, N. C., Johnstone, E. K. M., White, C. W. \& PFleGER, K. D. G. 2019. NanoBRET: The Bright Future of Proximity-Based Assays. Front Bioeng Biotechnol, 7, 1-13.

DIPILATO, L. M., CHENG, X. \& ZHANG, J. 2004. Fluorescent indicators of cAMP and Epac activation reveal differential dynamics of cAMP signaling within discrete subcellular compartments. Proc Natl Acad Sci U S A, 101, 16513-8. 
DRAKE, M. T., VIOLIN, J. D., WHALEN, E. J., WiSLER, J. W., SHENOY, S. K. \& LEFKOWITZ, R. J. 2008. $\beta$-arrestin-biased agonism at the $\beta_{2}$-adrenergic receptor. J Biol Chem,283, 5669-76.

EICHEL, K. \& VON ZASTROW, M. 2018. Subcellular Organization of GPCR Signaling. Trends Pharmacol Sci, 39, 200-208.

FERRANDON, S., FEINSTEIn, T. N., CASTRO, M., WANG, B., BOUley, R., POTTS, J. T., GARDELLA, T. J. \& VILARDAGA, J. P. 2009. Sustained cyclic AMP production by parathyroid hormone receptor endocytosis. Nat Chem Biol, 5, 734-42.

GALES, C., REBOIS, R. V., HOGUE, M., TRIEU, P., BREIT, A., HEBERT, T. E. \& BOUVIER, M. 2005. Real-time monitoring of receptor and G-protein interactions in living cells. Nat Methods, 2, 177-84.

GHANOUni, P., STEENHUIS, J. J., FARRENS, D. L. \& KOBILKA, B. K. 2001. Agonist-induced conformational changes in the G-protein-coupling domain of the $\beta_{2}$ adrenergic receptor. Proc Natl Acad Sci U S A, 98, 5997-6002.

GiUbilaro, J., SCHUETZ, D. A., STEPNIEWSKI, T. M., NAMKUnG, Y., KHOURY, E., LARAMARQUEZ, M., CAMPBElL, S., BEAUTRAit, A., ARMANDO, S., RADRESA, O., DUCHAINE, J., LAMARCHE-VANE, N., CLAING, A., SELENT, J., BOUVIER, M., MARINIER, A. \& LAPORTE, S. A. 2021. Discovery of a dual Ras and ARF6 inhibitor from a GPCR endocytosis screen. Nat Commun,12, 4688.

GODBOLE, A., LYGA, S., LOHSE, M. J. \& CALEBIRO, D. 2017. Internalized TSH receptors en route to the TGN induce local $\mathrm{G}_{\mathrm{s}}$-protein signaling and gene transcription. Nat Commun, 8, 443.

HALL, M. P., UNCH, J., BINKOWSKI, B. F., VAlley, M. P., BUTLER, B. L., WOOD, M. G., OTTO, P., ZIMMERMAN, K., VIDUGIRIS, G., MACHLEIDT, T., ROBERS, M. B., BENINK, H. A., EGGERS, C. T., SLATER, M. R., MEISENHEIMER, P. L., KLAUBERT, D. H., FAN, F., ENCELL, L. P. \& WOOD, K. V. 2012. Engineered luciferase reporter from a deep sea shrimp utilizing a novel imidazopyrazinone substrate. ACS Chem Biol, 7,1848-57.

HEIN, P., ROCHAis, F., HOFFMANN, C., DORSCH, S., NIKOlAEV, V. O., ENGElHARDT, S., BERLOT, C. H., LOHSE, M. J. \& BUNEMANN, M. 2006. $\mathrm{G}_{\mathrm{s}}$ activation is time-limiting in initiating receptor-mediated signaling. J Biol Chem, 281, 33345-51.

HEMPEL, C. M., VINCENT, P., ADAMS, S. R., TSIEN, R. Y. \& SELVERSTON, A. I. 1996. Spatiotemporal dynamics of cyclic AMP signals in an intact neural circuitm. Nature, 384, 166-9.

IRANNEJAD, R., PESSINO, V., MIKA, D., HUANG, B., WEDEGAERTNER, P. B., CONTI, M. \& VON ZASTROW, M. 2017. Functional selectivity of GPCR-directed drug action through location bias. Nat Chem Biol,13, 799-806.

IRANNEJAD, R., TOMShine, J. C., TOMSHINE, J. R., CHEVAliER, M., MAHONEY, J. P., STEYAERT, J., RASMUSSEN, S. G., SUNAHARA, R. K., EL-SAMAD, H., HUANG, B. \& VON ZASTROW, M. 2013. Conformational biosensors reveal GPCR signalling from endosomes. Nature, 495, 534-8.

JANETOPOUlOS, C., JIN, T. \& DEVREOTES, P. 2001. Receptor-mediated activation of heterotrimeric G-proteins in living cells. Science,291, 2408-11.

JEnSEN, D. D., LIEU, T., HAlls, M. L., VEldhuis, N. A., IMlACH, W. L., MAI, Q. N., POOLE, D. P., QUACH, T., AUREliO, L., CONNER, J., HERENBRINK, C. K., BARLOW, N., SIMPSON, J. S., SCANLON, M. J., GRAHAM, B., MCCLUSKEY, A., ROBINSON, P. J., ESCRIOU, V., NASSINI, R., MATERAZZI, S., GEPPETTI, P., HICKS, G. A., CHRISTIE, M. J., PORTER, C. J. H., CANALS, M. \& BUNNETT, N. W. 2017. Neurokinin 1 receptor signaling in endosomes mediates sustained nociception and is a viable therapeutic target for prolonged pain relief. Sci Transl Med, 9, eaal3447.

JIANG, L. I., COLliNS, J., DAVIS, R., LIN, K. M., DECAMP, D., ROACH, T., HSUEH, R., REBRES, R. A., ROSS, E. M., TAUSSIG, R., FRASER, I. \& STERNWEIS, P. C. 2007. Use of a cAMP BRET sensor to 
characterize a novel regulation of cAMP by the sphingosine 1-phosphate/G13 pathway. J Biol Chem, 282, 10576-84.

JIMENEZ-VARGAS, N. N., GONG, J., WISDOM, M. J., JENSEN, D. D., LATORRE, R., HEGRON, A., TENG, S., DICELlO, J. J., RAJASEKHAR, P., VELDHUIS, N. A., CARBONE, S. E., YU, Y., LOPEZLOPEZ, C., JARAMILLO-POLANCO, J., CANALS, M., REED, D. E., LOMAX, A. E., SCHMIDT, B. L., LEONG, K. W., VANNER, S. J., HALLS, M. L., BUNNETT, N. W. \& POOLE, D. P. 2020. Endosomal signaling of $\delta$-opioid receptors is an endogenous mechanism and therapeutic target for relief from inflammatory pain. Proc Natl Acad Sci U S A, 117, 15281-15292.

KIM, C., CHENG, C. Y., SALDANHA, S. A. \& TAYLOR, S. S. 2007. PKA-I holoenzyme structure reveals a mechanism for cAMP-dependent activation. Cell, 130, 1032-43.

KLARENBEEK, J. B., GOEDHART, J., HINK, M. A., GADELlA, T. W. \& JALINK, K. 2011. A mTurquoise-based cAMP sensor for both FLIM and ratiometric read-out has improved dynamic range. PLoS One, 6,e19170.

LAN, T. H., KURAVI, S. \& LAMBERT, N. A. 2011. Internalization dissociates $\beta_{2}$-adrenergic receptors. PLoS One,6, e17361.

LAN, T. H., LIU, Q., LI, C., WU, G. \& LAMBERT, N. A. 2012. Sensitive and high resolution localization and tracking of membrane proteins in live cells with BRET. Traffic, 13, 1450-6.

LiSSANDRON, V., TERRIN, A., COLlini, M., D'AlFOnSO, L., CHIRICO, G., PANTANO, S. \& ZACCOLO, M. 2005. Improvement of a FRET-based indicator for cAMP by linker design and stabilization of donor-acceptor interaction. J Mol Biol, 354, 546-55.

LOHSE, M. J., NUBER, S. \& HOFFMANN, C. 2012. Fluorescence/bioluminescence resonance energy transfer techniques to study G-protein-coupled receptor activation and signaling.Pharmacol Rev, 64, 299336.

LUCEY, M., ASHIK, T., MARZOOK, A., WANG, Y., GOULDING, J., OISHI, A., BROICHHAGEN, J., HODSON, D. J., MINNION, J., ELANI, Y., JOCKERS, R., BRIDDON, S. J., BLOOM, S. R., TOMAS, A. \& JONES, B. 2021. Acylation of the Incretin Peptide Exendin-4 Directly Impacts Glucagon-Like Peptide-1 Receptor Signaling and Trafficking. Mol Pharmacol, 100,319-334.

MARTIN, B. R. \& LAMBERT, N. A. 2016. Activated G Protein Galphas Samples Multiple Endomembrane Compartments. J Biol Chem,291, 20295-20302.

MASUho, I., OSTROVSKAyA, O., KRAMER, G. M., JONES, C. D., XIE, K. \& MARTEMYANOV, K. A. 2015. Distinct profiles of functional discrimination among $G$ proteins determine the actions of $\mathrm{G}$ protein-coupled receptors.Sci Signal, 8, ra123.

MATTHIESEN, K. \& NIELSEN, J. 2011. Cyclic AMP control measured in two compartments in HEK293 cells: phosphodiesterase $\mathrm{K}_{\mathrm{M}}$ is more important than phosphodiesterase localization. PLoS One,6, e24392.

MAZIARZ, M., PARK, J. C., LEYME, A., MARIVIN, A., GARCIA-LOPEZ, A., PATEL, P. P. \& GARCIAMARCOS, M. 2020. Revealing the Activity of Trimeric G-proteins in Live Cells with a Versatile Biosensor Design. Cell, 182, 770-785 e16.

MCGLONE, E. R., MANCHANDA, Y., JONES, B., PICKFORD, P., INOUE, A., CARLING, D., BLOOM, S. R., TAN, T. \& TOMAS, A. 2021. Receptor Activity-Modifying Protein 2 (RAMP2) alters glucagon receptor trafficking in hepatocytes with functional effects on receptor signalling. Mol Metab, 53, 101296.

MERKLE, F. T., NEUHAUSSER, W. M., SANTOS, D., VAlEN, E., GAGNON, J. A., MAAS, K., SANDOE, J., SCHIER, A. F. \& EGGAN, K. 2015. Efficient CRISPR-Cas9-mediated generation of knockin human pluripotent stem cells lacking undesired mutations at the targeted locus. Cell Rep,11, 875-883. 
NeHMe, R., CARPENTER, B., Singhal, A., STREGE, A., EDWARDS, P. C., White, C. F., DU, H., GRISSHAMMER, R. \& TATE, C. G. 2017. Mini-G proteins: Novel tools for studying GPCRs in their active conformation.PLoS One, 12, e0175642.

NIKOlAEV, V. O., BUNEMANn, M., HEIN, L., HANNAWACKER, A. \& LOHSE, M. J. 2004. Novel single chain cAMP sensors for receptor-induced signal propagation. $J$ Biol Chem, 279, 37215-8.

NOBLES, M., BENIANS, A. \& TINKER, A. 2005. Heterotrimeric G proteins precouple with G proteincoupled receptors in living cells. Proc Natl Acad Sci U S A, 102, 18706-11.

PARAMONOV, V. M., MAMAEVA, V., SAHLGREN, C. \& RIVERO-MULLER, A. 2015. Geneticallyencoded tools for cAMP probing and modulation in living systems. Front Pharmacol, 6, 196.

PHILIP, F., SENGUPTA, P. \& SCARLATA, S. 2007. Signaling through a G Protein-coupled receptor and its corresponding G protein follows a stoichiometrically limited model. J Biol Chem, 282,19203-16.

PONSIOEN, B., ZHAO, J., RIEDL, J., ZWARTKRUIS, F., VAN DER KROGT, G., ZACCOLO, M., MOOLENAAR, W. H., BOS, J. L. \& JALINK, K. 2004. Detecting cAMP-induced Epac activation by fluorescence resonance energy transfer: Epac as a novel cAMP indicator. EMBO Rep, 5, 1176-80.

PRINZ, A., DISKAR, M., ERLBRUCH, A. \& HERBERG, F. W. 2006. Novel, isotype-specific sensors for protein kinase A subunit interaction based on bioluminescence resonance energy transfer (BRET). Cell Signal,18, 1616-25.

RASMUSSEN, S. G., CHOI, H. J., FUnG, J. J., PARDON, E., CASAROSA, P., CHAE, P. S., DEVREE, B. T., ROSENBAUM, D. M., THIAN, F. S., KOBILKA, T. S., SCHNAPP, A., KONETZKI, I., SUNAHARA, R. K., GELLMAN, S. H., PAUTSCH, A., STEYAERT, J., WEIS, W. I. \& KOBILKA, B. K. 2011. Structure of a nanobody-stabilized active state of the beta(2) adrenoceptor. Nature, 469, 175-80.

SEKAR, R. B. \& PERIASAMY, A. 2003. Fluorescence resonance energy transfer (FRET) microscopy imaging of live cell protein localizations.J Cell Biol, 160, 629-33.

SOAVE, M., STODDART, L. A., BROWN, A., WOOLARD, J. \& HILL, S. J. 2016. Use of a new proximity assay (NanoBRET) to investigate the ligand-binding characteristics of three fluorescent ligands to the human $\beta_{1}$-adrenoceptor expressed in HEK-293 cells.Pharmacol Res Perspect, 4, e00250.

STODDART, L. A., JOHNSTONE, E. K. M., WHEAL, A. J., GOULDING, J., ROBERS, M. B., MACHLEIDT, T., WOOD, K. V., HILL, S. J. \& PFLEGER, K. D. G. 2015. Application of BRET to monitor ligand binding to GPCRs.Nat Methods, 12, 661-663.

SU, Y., WALKER, J. R., PARK, Y., SMITH, T. P., LIU, L. X., HALL, M. P., LABANIEH, L., HURST, R., WANG, D. C., ENCELL, L. P., KIM, N., ZHANG, F., KAY, M. A., CASEY, K. M., MAJZNER, R. G., COCHRAN, J. R., MACKALL, C. L., KIRKLAND, T. A. \& LIN, M. Z. 2020. Novel NanoLuc substrates enable bright two-population bioluminescence imaging in animals. Nat Methods, 17, 852-860.

TIUlPAKOV, A., White, C. W., ABHAYAWARDANA, R. S., SEE, H. B., CHAN, A. S., SEEBER, R. M., HENG, J. I., DEDOV, I., PAVLOS, N. J. \& PFLEGER, K. D. 2016. Mutations of Vasopressin Receptor 2 Including Novel L312S Have Differential Effects on Trafficking. Mol Endocrinol, 30,889-904.

TSVETANOVA, N. G. \& VON ZASTROW, M. 2014. Spatial encoding of cyclic AMP signaling specificity by GPCR endocytosis. Nat Chem Biol,10, 1061-5.

WAN, Q., OKASHAH, N., INOUE, A., NEHME, R., CARPENTER, B., TATE, C. G. \& LAMBERT, N. A. 2018. Mini G protein probes for active G protein-coupled receptors (GPCRs) in live cells. J Biol Chem,293, 7466-7473.

WERThMANN, R. C., VOLPE, S., LOHSE, M. J. \& CALEBIRO, D. 2012. Persistent cAMP signaling by internalized TSH receptors occurs in thyroid but not in HEK293 cells. FASEB J, 26, 2043-8. 
White, C. W., VANYAI, H. K., SEE, H. B., JOHnStOnE, E. K. M. \& PFLEGER, K. D. G. 2017. Using nanoBRET and CRISPR/Cas9 to monitor proximity to a genome-edited protein in real-time. Sci Rep, 7, 3187.

WRight, S. C., LUKASHEVA, V., LE GOUILl, C., KOBAYASHI, H., BRETON, B., MAILHOTLAROUCHE, S., BLONDEL-TEPAZ, E., ANTUNES VIEIRA, N., COSTA-NETO, C., HEROUX, M., LAMBERT, N. A., PARREIRAS, E. S. L. T. \& BOUVIER, M. 2021. BRET-based effector membrane translocation assay monitors GPCR-promoted and endocytosis-mediated $\mathrm{G}_{\mathrm{q}}$ activation at early endosomes. Proc Natl Acad Sci U S A, 118.

YARWOOD, R. E., IMLACH, W. L., LIEU, T., VELDHUIS, N. A., JENSEN, D. D., KLEIN HERENBRINK, C., AURElio, L., CAI, Z., Christie, M. J., POOle, D. P., PORTER, C. J. H., MClEAN, P., HICKS, G. A., GEPPETTI, P., HALlS, M. L., CANALS, M. \& BUNNETT, N. W. 2017. Endosomal signaling of the receptor for calcitonin gene-related peptide mediates pain transmission.Proc Natl Acad Sci U S A, 114, 12309-12314.

ZACCOlO, M., DE GIORGI, F., CHO, C. Y., FENG, L., KNAPP, T., NEGUlESCU, P. A., TAYLOR, S. S., TSIEN, R. Y. \& POZZAN, T. 2000. A genetically encoded, fluorescent indicator for cyclic AMP in living cells. Nat Cell Biol, 2, 25-9.

ZACHARIAS, D. A., VIOLIN, J. D., NEWTON, A. C. \& TSIEN, R. Y. 2002. Partitioning of lipid-modified monomeric GFPs into membrane microdomains of live cells. Science, 296, 913-6.

ZHANG, J., MA, Y., TAYLOR, S. S. \& TSIEN, R. Y. 2001. Genetically encoded reporters of protein kinase A activity reveal impact of substrate tethering. Proc Natl Acad Sci U S A, 98,14997-5002.

E.T. is funded by the Medical Research Council Integrated Midlands Partnership for Biomedical Training (MRC IMPACT) doctoral training programme awarded to the University of Birmingham.

This work was partially supported by a Wellcome Trust Senior Research Fellowship (212313/Z/18/Z to D.C.).

Competing Interests' Statement: none 


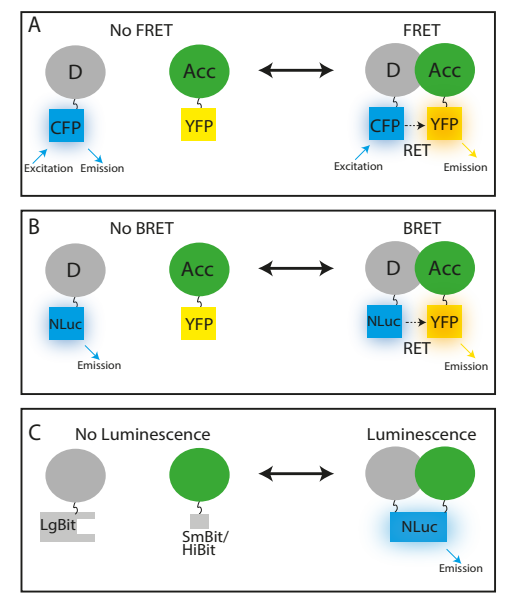


A

GPCR

activation

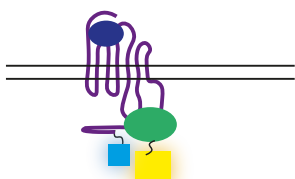

mini-G/
Nanobody

CFP/Nluc/Rluc

YFP/GFP

Ligand
B

Compartmentalised GPCR signalling
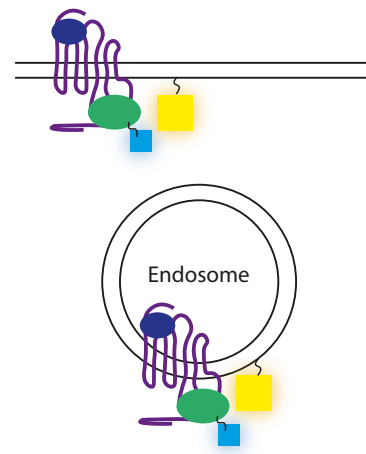

C

GPCR trafficking

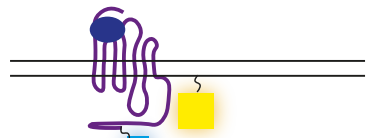

(x)

(

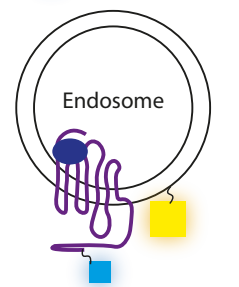

